\title{
Nonlinear Effects of Intraspecific Competition Alter Landscape-Wide Scaling Up of Ecosystem Function
}

\author{
Chelsea J. Little, ${ }^{1,2,}$ Emanuel A. Fronhofer, ${ }^{1,2,3}$ and Florian Altermatt ${ }^{1,2}$ \\ 1. Department of Evolutionary Biology and Environmental Studies, University of Zurich, Winterthurerstrasse 190, CH-8057 Zurich, \\ Switzerland; 2. Department of Aquatic Ecology, Swiss Federal Institute of Aquatic Science and Technology, Überlandstrasse 133, CH-8600 \\ Dübendorf, Switzerland; 3. ISEM, Univ Montpellier, CNRS, EPHE, IRD, 34095 Montpellier, France \\ Submitted April 16, 2019; Accepted July 29, 2019; Electronically published January 17, 2020 \\ Online enhancements: appendixes, supplemental PDF, code files. Dryad data: https://doi.org/10.5061/dryad.3124p62.
}

\begin{abstract}
A major focus of ecology is to understand and predict ecosystem function across scales. Many ecosystem functions are measured only at local scales, while their effects occur at a landscape level. Here we investigate how landscape-scale predictions of ecosystem function depend on intraspecific competition, a fine-scale process, by manipulating intraspecific density of shredding macroinvertebrates and examining effects on leaf litter decomposition, a key function in freshwater ecosystems. For two species, we found that per capita leaf processing rates declined with increasing density following power functions with negative exponents, likely due to interference competition. To demonstrate consequences of this nonlinearity, we scaled up estimates of leaf litter processing from shredder abundance surveys in 10 replicated headwater streams. In accordance with Jensen's inequality, applying densitydependent consumption rates reduced estimates of catchment-scale leaf consumption by an order of magnitude relative to density-independent rates. Density-dependent consumption estimates aligned closely with metabolic requirements in catchments with large - but not smallshredder populations. Importantly, shredder abundance was not limited by leaf litter availability, and catchment-level leaf litter supply was much higher than estimated consumption. Thus leaf litter processing was not limited by resource supply. Our work highlights the need for scaling up, which accounts for intraspecific interactions.
\end{abstract}

Keywords: decomposition, Jensen's inequality, leaf litter, macroinvertebrates, scaling up, shredders.

\section{Introduction}

In an era of ongoing global change, a growing focus of ecology is to understand what controls ecosystem function-

\footnotetext{
* Corresponding author. Present address: Department of Zoology, University of British Columbia, Vancouver, British Columbia, Canada V6T 1Z4; email: chelsea.little.does.ecology@gmail.com.

ORCIDs: Little, https://orcid.org/0000-0003-2803-7465; Frohnhofer, https:// orcid.org/0000-0002-2219-784X; Altermatt, https://orcid.org/0000-0002-4831 $-6958$.
}

Am. Nat. 2020. Vol. 195, pp. 432-444. @ 2020 by The University of Chicago. 0003-0147/2020/19503-59188\$15.00. All rights reserved.

DOI: $10.1086 / 707018$ ing and to predict future scenarios of ecosystem function and services. Biodiversity is an important determinant of ecosystem functioning: the traits and dynamics of individuals and species interact to determine the flow of energy and resources through an ecosystem (Hines and Gessner 2012; Grace et al. 2016; Moore and Olden 2017; O'Connor et al. 2017). The number of species in a community is an important determinant of its functioning, not just as a sum of these traits and functions but also due to interactions between organisms, which can be synergistic or antagonistic (Downing and Leibold 2002; Carrara et al. 2015). Thus the relative abundance of species is important because the presence of common or dominant species, for example, can influence the relationship between biodiversity and ecosystem function (Smith and Knapp 2003; Dangles and Malmqvist 2004; Winfree et al. 2015). Relative abundance and community assembly are increasingly being incorporated into biodiversity-ecosystem function (BEF) frameworks (e.g., Bannar-Martin et al. 2018) as well as being implicitly included in metrics such as evenness and functional diversity, which are sometimes associated with ecosystem function (Hillebrand et al. 2008).

The BEF framework has primarily focused on interspecific interactions (but see Raffard et al. 2019). However, intraspecific density-dependent interactions are also recognized as important in almost all disciplines of ecology. For example, they are a key requirement for the maintenance of biodiversity, according to modern coexistence theory (Chesson 2000; Amarasekare 2003; McPeek 2012), and many aspects of population dynamics are controlled by density (Hassell et al. 1976; Brook and Bradshaw 2006). Yet intraspecific competition and other density-dependent dynamics rarely appear in BEF schemes partitioning the contribution of different species in a community to ecosystem function (however, see Parain et al. 2018). This is a surprising gap because variation in intraspecific density is ubiquitous in nature: there is considerable variation in species abundances through space and time (Hanski 1990). 
Thus, density-dependent control of ecosystem function is not just potentially substantial in magnitude but could be widespread. The consequences of this mechanism for landscape-level ecosystem functioning remain unexplored, particularly with regard to understanding the shape of a density-ecosystem function (henceforth DEF). Nonlinear relationships abound in nature and affect the accuracy of scaling up (Harvey 2000), yet nonlinearities arising from intraspecific interactions are not currently taken into account. Analogous to functional and temperature response curves, nonlinear DEF relationships would mean that scaling up based on knowledge of ecosystem function at one scale could greatly over- or underpredict gross rates at a broader scale. This idea is captured by Jensen's inequality, which shows that for nonlinear functions, the mean value of the function across a set of $x$ values is not equivalent to the value of the function at the mean of $x$ (Jensen 1906), a property that has important consequences for interpreting ecological data (Ruel and Ayres 1999; Martin and Huey 2008; Kingsolver 2009; Denny and Benedetti-Cecchi 2012).

The DEF relationship may be most relevant in determining ecosystem functioning in cases where dominant or highly abundant species contribute a large part of a specific ecosystem function. Widely known and large-effectsize examples include salmon importing and exporting nutrients to watersheds (Rüegg et al. 2011) and Daphnia clearing lakes of phytoplankton, contributing to secondary production and controlling ecosystem metabolism (Winder and Schindler 2004; Birtel and Matthews 2016). In these cases, a large part of ecosystem function could be predicted by understanding the dynamics of these key taxa, without also considering the comparatively small contributions of rarer taxa. Furthermore, species richness is typically lower where a species is dominant both locally and regionally (Hillebrand et al. 2008), meaning that even in local patches where the dominant species is absent, there may be few other species to provide the same function. For example, in a French stream network, the dominant shredding macroinvertebrate declined in abundance with agricultural intensity, but even where it was absent, there were no other taxa that could replace its function in the decomposition process (Piscart et al. 2009). Thus, spatial insurance effects often associated with species turnover (Yachi and Loreau 1999; Loreau et al. 2003) were not present in a way that could maintain this ecosystem function.

In fact, decomposition in freshwater ecosystems may be an ideal setting to explore DEF relationships. Decomposition regulates resource cycling and is particularly important in aquatic systems where terrestrial detritus can make up a large portion of resource fluxes (Gounand et al. 2018). Furthermore, the characteristic spatial structure of stream networks and the way in which aquatic organisms are limited to dispersing through a stepping-stone arrange- ment of habitat patches can limit community assembly (Drakou et al. 2009; Brown et al. 2011; Altermatt 2013; Sarremejane et al. 2017; Little and Altermatt 2018a). Perhaps partly as a result of this, communities of species contributing to decomposition are characteristically less complex in freshwater than terrestrial ecosystems (Hieber and Gessner 2002), and as a result, density variation in those few species could have a large impact (Jonsson and Malmqvist 2003; Klemmer et al. 2012). Decomposition (both in aquatic and terrestrial systems) is less frequently considered in ecosystem function frameworks than is terrestrial biomass production (Cardinale et al. 2011), which may partly explain why DEF has received relatively little attention: for terrestrial producers, a high diversity of species contributes to ecosystem function through time.

Here we investigate the relationship between intraspecific density of two aquatic macroinvertebrate shredders and their rate of leaf litter processing. To illustrate the potential importance of a nonlinear DEF relationship, we then use these DEF functions to scale up leaf litter processing estimates to the catchment level. We do so across 10 independent headwater stream networks, varying both in intraspecific density of shredders and abundance of leaf litter. Previous scalingup approaches assumed density independence of leaf processing rates and equal densities throughout a catchment (e.g., Piscart et al. 2011). By contrast, we incorporate spatial variance in shredder abundance and examine qualitative differences in results from scaling-up scenarios with and without this spatial variance, for two reasons. First, a previous meta-analysis of laboratory studies indicated density dependence in per capita leaf consumption rates (Little and Altermatt 2018c). Second, in this group of shredding macroinvertebrates, typically one species dominates locally, but the dominant species varies in abundance over orders of magnitude within a catchment (Welton 1979; Van den Brink et al. 1991; Altermatt et al. 2016; Little and Altermatt 2018a). This creates an ideal scenario to test the concept of a DEF relationship whereby the abundance of these key taxa - rather than species richness - could control decomposition and thus would need to be considered in scaling-up predictions.

\section{Methods \\ Study Organisms}

We experimentally assessed effects of intraspecific density on leaf shredding rates by two freshwater amphipod (Crustacea, Amphipoda) species: Gammarus fossarum (Koch), a relatively small species native to Central Europe, and Dikerogammarus villosus (Sowinsky), a relatively large species native to the Ponto-Caspian region that has recently invaded many regions worldwide (Van den Brink et al. 1991; Gallardo and Aldridge 2015; Šidagytė et al. 2017). As a guild, 
amphipods are the dominant invertebrates in the shredding functional group in many central European streams (e.g., Piscart et al. 2009; Nery and Schmera 2015). Collection and maintenance of study organisms are described in appendix A (apps. A, B are available online).

\section{Mesocosm Experiments}

Mesocosms were built from 2-L plastic containers with $0.4 \mathrm{~m}^{2}$ of bottom surface area placed in a flowing-water rack system with a mixture of stream and tap water. Conditioned senescent alder leaves totalling $1.5 \mathrm{~g}$ (dry weight) were placed in each mesocosm. Alder is commonly found in benthic leaf litter samples in headwater streams in this area (Little and Altermatt 2018b) and is a preferred food source for these species (Little and Altermatt 2018c). For each species, mesocosms were set up with fixed densities of the target amphipod species: 50 replicates with one individual, 20 replicates with two individuals, 10 with five individuals, 10 with 10 individuals, six with 20 individuals, and six with 30 individuals per mesocosm. This 30-fold density range is smaller than the $>100$-fold density range commonly observed in stream reaches (Little and Altermatt 2018a). The unbalanced number of replicates for each density was chosen because per-mesocosm leaf consumption was expected to be more variable in replicates with fewer amphipods.

The leaf consumption experiments were run for 19 (G. fossarum) and 12 (D. villosus) days, respectively, at which point leaves from the mesocosms were collected and dried for $48 \mathrm{~h}$ at $60^{\circ} \mathrm{C}$ and then weighed to calculate mass loss from the beginning of the experiment. At least 0.65 and $0.55 \mathrm{~g}$ of leaf litter remained at the end of the experiment for G. fossarum and D. villosus, respectively (representing $\geq 43 \%$ and $\geq 36 \%$ of the resources initially available). Amphipods were counted every 2-3 days throughout the experiments to track mortality; overall, survival was $89.3 \%$ for G. fossarum and $95.1 \%$ for D. villosus. These mortality estimates were used to calculate an average amphipod density (individuals per square meter) that the mesocosm experienced over the length of the experiment. At the end of the experiment, amphipods were sacrificed, dried for $48 \mathrm{~h}$ at $60^{\circ} \mathrm{C}$, and weighed. Individuals that died during the course of the experiment were assigned the global average weight of all amphipods across the experiment. The average daily biomass in a meso$\operatorname{cosm}\left(\mathrm{mg} \mathrm{m}^{-2}\right)$ was then calculated as the average density multiplied by the average weight of all individuals in the mesocosm. Two outliers were removed from the G. fossarum data set and three from the $D$. villosus data set, because their consumption rate estimates were more than 3 SD from the mean and substantially higher than any we had measured in previous experiments (Little and Altermatt 2018c).

\section{DEF Models}

For both amphipod species, we tested for the effects of density on leaf consumption using nonlinear models in R, version 3.5.0 (R Core Team 2018). Initial data exploration and linear models using transformed and nontransformed data showed that these relationships were linear in log-log space (for details, see app. A; figs. A1-A3; figs. A1-A4, B1, S1-S9 are available online). Therefore, we created negative power function models using the gNLS function in the nlme package, version 3.1-137 (Pinheiro et al. 2013) and weighted data points by the variance in the response variable, since there was higher variance around high estimates of leaf litter consumption across the experiment. For each species, we created separate models of the relationships between amphipod density and per-amphipod daily leaf consumption and between amphipod biomass daily leaf consumption per milligram of amphipod biomass.

\section{Field Surveys and Scaling Up of Shredder Abundance}

We scaled up estimates of leaf litter processing to the catchment level by pairing the derived DEF equations with spatially resolved population density data from field surveys. We had previously assessed amphipod abundance in 10 headwater stream catchments in eastern Switzerland predominantly inhabited by G. fossarum, where D. villosus was present only rarely at the outlets (Altermatt et al. 2016; Little and Altermatt 2018a); the latter species is more common in rivers (Van den Brink et al. 1991). The goal of scaling up was to demonstrate the consequences of nonlinear DEF relationships in natural ecosystems, so we focused on scaling up G. fossarum, which is common in these catchments (but see table S3 for scaling up with D. villosus; tables S1-S3, A1 are available online). The full details of the field surveys are described in Little and Altermatt (2018a), but briefly, sampling points were established in April 2015 in every $\sim 250$-m section of each stream. Amphipods were collected using a kick net, and their density was estimated on a logarithmic scale $(0,1-10,11-100,101-1,000$, or $>1,000$ individuals/meter-long stream segment; segments had a median and modal width of $1 \mathrm{~m}$, mean $=1.15 \pm 0.55 \mathrm{~m}^{2} \mathrm{SD}$ ). Below, we refer to these abundance estimates as bins.

For scaling up, we longitudinally divided each stream's mapped watercourse (swisstopo 2007) into 1-m segments and used two different methods to estimate the total abundance of amphipods in the catchment: inverse distance weighted interpolation and proportional estimation. We simulated spatial abundances of amphipods 1,000 times per catchment using each method and averaged over the simulations to extract catchment-wide predictions of abundance and processing (see below). 
Inverse distance weighting (IDW) produces interpolated data that varies smoothly in space as a function of distance from measured sampling points, based on the assumption that points close to one another are more similar. Each IDW simulation began by assigning the catchment's sampling points $(n=9-15$, depending on the catchment) to a random abundance value within their observed abundance bin (e.g., a random number between 11 and 100 for a bin with 11-100 individuals). Then using the package gstat, version 1.1-6 (Pebesma 2004), each 1-m segment was assigned an abundance based on its distance from these $9-15$ assigned points.

With the proportional estimation method, we removed the assumption that nearby reaches are more similar to one another and instead focused only on capturing the observed variation in surveyed abundances. With this method, we recorded the proportion of a catchment's sampling points that belonged to each abundance bin (i.e., proportion of sampling points with zero amphipods, proportion with 1-10 amphipods, etc.) and created a probability distribution of abundance bin assignment for the catchment. For a simulation, every 1-m stream segment was randomly assigned to an abundance bin based on this probability function, and then the segments were assigned random abundances from within the range of their assigned bins (e.g., assigned to the 1-10 amphipod bin and then assigned a random number between 1 and 10).

For each simulation, the 1-m segments were summed to produce a catchment-level abundance estimate. The 1,000 simulations per catchment (per method) were summarized with means and $95 \%$ confidence intervals (CIs).

\section{Scaling Up Processing Rates to Real Catchments}

We estimated whole catchments' total leaf litter processing rates per day based on these abundance estimates, under two scenarios. In scenario 1, we multiplied the global average per capita processing rate from the G. fossarum density experiment (i.e., average across all densities) by the total population size of the catchment, a common way to scale up consumption estimates (e.g., Piscart et al. 2011). In scenario 2 , we used the spatially varying amphipod densities derived from the two estimation methods and applied the experimentally derived G. fossarum DEF function to each 1-m stream segment before summing to the catchment level.

To compare these estimates to another frame of reference for understanding organisms' food consumption rates, we also estimated catchment-level leaf litter consumption rates based on metabolic requirements. We converted the total estimated abundance of G. fossarum in each catchment to biomass by multiplying their number by the average dry mass of G. fossarum used in the mesocosm experiments, $2.85 \mathrm{mg}$. We then estimated the amount of leaf litter consumption required by this biomass of amphipods on an annual scale, using three steps: (1) The production: biomass ratio $(P / B)$ represents the ratio of the new biomass $P$ that a population of current biomass $B$ is expected to add annually. We set $P / B$ at 3.5 , as in prior woodland stream macroinvertebrate work (Petersen et al. 1989); this is intermediate between $P / B$ estimates of congeneric taxa, including 4.29 for lake amphipods (Zhang et al. 2016), 4.65 for Gammarus pseudolimnaeus in a river (Marchant and Hynes 1981), and 2.6 for Gammarus pulex in a stream (Mortensen 1982). (2) Resources are required both for production and basic metabolic maintenance; as such, the ratio of respiration: production for macroinvertebrates has been estimated at 70:30 (Cummins 1975), such that 0.3 is the production: assimilation ratio $(P / A)$. (3) Finally, European freshwater amphipods have a 0.4 assimilation: consumption ratio $(A / C)$ of conditioned leaves (Gergs and Rothhaupt 2008). Thus, per milligram of amphipod biomass, we inverted the $P / A$ and $A / C$ ratios and calculated

$$
\text { consumption }=\text { biomass } \times 3.5 \frac{P}{B} \times 3.33 \frac{A}{P} \times 2.5 \frac{C}{A} .
$$

For additional details on the metabolic requirement estimation, see appendix B.

\section{Leaf Litter Availability in Real Catchments}

In parallel to assessing amphipod densities for scaling up processing rates, we also assessed the availability (abundance) of leaf litter in the stream catchments at the same spatiotemporal resolution (Little and Altermatt 2018b). This allowed us to put the processing rates into context and could be used to determine whether processing of leaves was donor limited (i.e., whether leaf litter was consistently available as a food resource). We used two methods to assess leaf litter supply and compare it to the estimated demands from the scaling-up estimates. First, at the same sampling points in the 10 catchments where we surveyed amphipod abundance, we concurrently measured benthic leaf litter standing stock four times over the course of a year (Little and Altermatt 2018b). Briefly, at each sampling point and at each sampling visit, the substrate of the 1-m-long stream segment was classified into substrate types and vegetation and benthic leaf litter cover using a $1 \times 1$-m sampling frame with $0.2 \times 0.2$-m grid lines (for details, see Little and Altermatt 2018a, 2018c). Then all benthic leaf litter was collected from a known subsample of area (mean area collected $=0.032 \pm 0.012 \mathrm{~m}^{2} \mathrm{SD}$ ), and the substrate area of the subsample as a proportion of the total amount of streambed covered in leaf litter in that stream segment was used to calculate the standing stock of leaf litter (in $g$ dry weight $\mathrm{m}^{-2}$ ) at that sampling point. We a priori hypothesized that amphipod distributions would be correlated 
with leaf litter availability; however, this was only minimally borne out in a joint species distribution model based on amphipod presence/absence (Little and Altermatt 2018a). To assess whether amphipod abundance was correlated with leaf litter availability, here we summarized the distribution of benthic leaf litter standing stock measurements for each abundance class of amphipods. We made a linear mixedeffect model using the lme4 package, version 1.1-18-1 (Bates et al. 2015), with benthic leaf litter as a fixed factor, sampling point and season as random factors to account for repeated sampling visits, and the square-root transformed minimum of the abundance class as the response variable. The significance of the fixed factor was assessed using a type III analysis of variance with Satterthwaite's method using the lmerTest package, version 3.0-1 (Kuznetsova et al. 2015).

Second, we estimated annual leaf litter input to each of the 10 catchments by combining field sampling with land cover data. We deployed leaf litter traps $(n=8$ per site, collecting an area of $800 \mathrm{~cm}^{2}$ each) at six different sites (three deciduous forest, one mixed forest, two agricultural) during the fall leaf drop (September 8-December 1, 2015). We then paired this with data on land cover within a 1-m buffer zone on either side of each stream (for detailed methods, see app. B). This represents a conservative estimate of leaf litter input because we did not measure lateral blow-in, which occurs throughout the year and can represent an additional $\sim 20 \%-50 \%$ of total leaf litter inputs to forested headwater streams (Fisher and Likens 1973; Conners and Naiman 2008; Kochi et al. 2010).

\section{Results}

Our experimental data of per capita consumption rates and density fit power functions with negative exponents (for fitting details, see app. A). This was true when relating both individual density to per capita leaf consumption (fig. 1) and density of biomass to biomass-adjusted leaf consumption (fig. A4). To confirm that these derived relationships explained the density-dependent relationship with per capita consumption rates, we calculated predicted per-mesocosm total leaf consumption along a continuous gradient of amphipod densities. These curves (solid lines in right panels of fig. 1) reasonably matched the actual per-mesocosm leaf consumption rates, while linear extrapolations based on density-independent, constant per capita consumption rates overestimated total leaf consumption by orders of magnitude for any density greater than a few amphipods per square meter (fig. 1). Data underlying this figure and all subsequent analyses have been deposited in the Dryad Digital Repository (https://doi.org/10.5061/dryad.3124p62; Little et al. 2020).

Next we scaled up amphipod abundance estimates in the 10 study catchments. Estimates of whole-catchment abundance ranged from hundreds (808 in Dorfbach) to millions
(1.46 million in Mannenbach) of amphipods using the IDW estimation method (table 1) and from thousands (1,590 in Dorfbach) to millions (1.43 million in Seebach) using proportional estimation (table $\mathrm{S} 1$ ).

In an example catchment, the Chesselbach (for all other catchments, see table S1; figs. S1-S9) IDW interpolation from 13 sampling points (fig. 2) produced an estimate of $\sim 720,000$ amphipods in the catchment (mean of 1,000 simulations: 720,$719 ; 95 \%$ CI: 709,980-731,456). Using the mean experimental per capita consumption rate $(12.5 \mathrm{mg}$ amphipod $^{-1}$ day $^{-1}$ ) to derive leaf processing (scenario 1) yielded a mean of $9.02 \mathrm{~kg}$ of leaf litter (dry weight) processed per day. Applying the experimentally derived negative DEF relationship to the spatially varying interpolated densities in the catchment (scenario 2) resulted in a markedly lower predicted processing rate, in this case, a mean of $0.3 \mathrm{~kg}$ per day. Indeed, in all but one (the most sparsely occupied) catchment, estimates of total leaf litter processing were lower using the experimentally derived DEF relationship than when using a density-independent processing rate (table 1). The mismatch was substantial: not accounting for density dependence resulted in leaf processing rates up to 50 times higher in some catchments. Results were similar when based on proportional abundance estimations (table S1). However, average consumption rates will necessarily vary across experiments depending on the densities in experimental units, as we demonstrate in figure 1, so the global average consumption rate from our experimentwhich includes both a wider range of densities and a higher maximum density than typically used in amphipod leaf consumption experiments (Little and Altermatt 2018c) may actually lead to a less drastic overestimation than would be produced by using average consumption rates from experiments that used only single-individual mesocosms, for example. The processing estimates based on scenario 2 corresponded well with estimated metabolic requirements for amphipod populations of the estimated size (table 1). In all catchments with total abundance greater than 500,000 amphipods, which corresponded to average densities of more than 100 amphipods per meter of stream length, the metabolic estimate was within $50 \%$ of the scenario 2 estimates. The scenario 1 estimates, by contrast, were 50 times greater than the estimated metabolic requirements.

Greater benthic leaf litter standing stock did not correspond to higher abundances of amphipods (fig. 3): the fixed and random factors combined explained more variance (conditional $R^{2}=0.29$ ) than the fixed factors alone (marginal $R^{2}=0.01$ ), and the fixed factor of leaf litter availability was not significantly associated with amphipod abundance $\left(F_{1,402}=0.14, p=.70\right)$. This was congruent with its overall low contribution to variation in amphipod presence/absence when assessed together with other explanatory variables such as water chemistry, land 

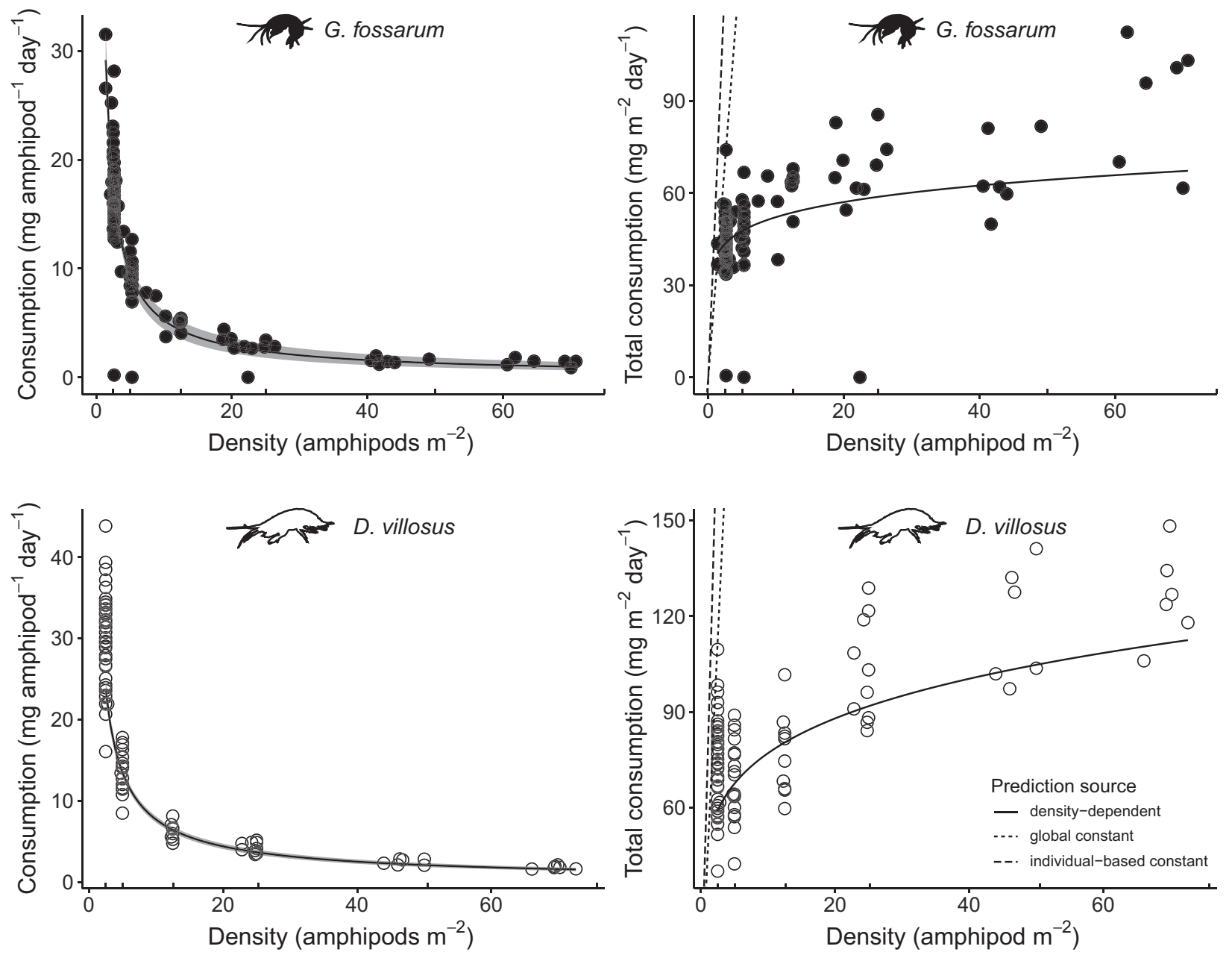

Figure 1: Left, negative power functions relating density and per capita consumption rates for Gammarus fossarum (consumption = $38.6 \times$ density $^{-0.87}$; top) and Dikerogammarus villosus (consumption $=49.7 \times$ density $^{-0.81}$; bottom) in mesocosm experiments. Gray shading shows the $95 \%$ confidence interval of the model fit. Right, total daily leaf litter consumption per mesocosm, overlaid by expected values from the negative power functions derived at left (solid lines), constant per capita consumption rates calculated by averaging all mesocosms (dotted lines), and constant per capita consumption rates calculated only from mesocosms with one individual amphipod each (dashed lines). Note the different $X$ - and $Y$-axis ranges for the two species. Vertical tick marks above the $X$-axis indicate starting densities for experimental mesocosms. Data underlying this and all figures have been deposited in the Dryad Digital Repository (https://doi.org/10.5061/dryad .3124p62; Little et al. 2020).

use, and microhabitat (Little and Altermatt 2018a). However, low values of standing stock could be due to multiple mechanisms, including low input rates, high processing rates, or flushing downstream. Therefore, we also estimated total leaf litter input rates. From leaf litter traps deployed in forested areas capturing vertical litter fall during the fall leaf drop period, an average of $478 \mathrm{~g} \mathrm{~m}^{-2}$ (dry weight) of litter inputs were available annually (range: 373-509 $\mathrm{g} \mathrm{m}^{-2}, n=4$ sites; fig. A4). We then mapped these inputs onto land cover patterns in the catchments. All but four catchments had $>50 \%$ of their $1-\mathrm{m}$ buffer zone in forested areas, and these four catchments had $53 \%-91 \%$ of their buffer area in riparian strip vegetation (fig. 4A). Overall, nonshrub/tree cover accounted for only $2 \%-28 \%$ of the near-stream buffer zone, except for one outlier catchment (Seebach), for which it represented $47 \%$ of the buffer area (fig. $4 A$ ). Seebach thus had the lowest estimated leaf litter inputs ( $\left.77 \mathrm{~kg}_{\mathrm{kear}}{ }^{-1}\right)$, while the other catchments received an estimated 1,084-3,533 kg of leaf litter from their directly adjacent vegetation annually (fig. $4 B$ ). For most catchments, this was substantially more leaf litter than we estimated to be consumed annually under scenario 2, which incorporated spatial heterogeneity in abundances as well as density-dependent consumption (fig. 4B). At the extremes, in a sparsely inhabited but heavily vegetated catchment (Dorfbach), input was 700 times the estimated 
Table 1: Total amphipod abundance estimated using inverse distance weighted interpolation from field sampling and three estimates of whole-catchment leaf litter processing (grams/day)

\begin{tabular}{|c|c|c|c|c|c|c|}
\hline Stream name & $n$ & $\begin{array}{l}\text { Length } \\
(\mathrm{km})\end{array}$ & $\begin{array}{c}\text { Total } \\
\text { abundance }\end{array}$ & $\begin{array}{l}\text { Scenario } 1 \\
\text { processing }\end{array}$ & $\begin{array}{l}\text { Scenario } 2 \\
\text { processing }\end{array}$ & $\begin{array}{l}\text { Metabolic } \\
\text { requirement }\end{array}$ \\
\hline Chesselbach & 13 & 4.5 & $\begin{array}{r}720,719 \\
( \pm 1,035)\end{array}$ & $\begin{array}{c}9,023.9 \\
( \pm 134.4)\end{array}$ & $\begin{array}{c}325.9 \\
( \pm .6)\end{array}$ & $\begin{array}{c}164.1 \\
( \pm .2)\end{array}$ \\
\hline Dorfbach & 15 & 4.3 & $\begin{array}{r}808 \\
( \pm 6)\end{array}$ & $\begin{array}{l}10.1 \\
( \pm .3)\end{array}$ & $\begin{array}{l}10.0 \\
( \pm .2)\end{array}$ & $\begin{array}{c}.2 \\
( \pm .0)\end{array}$ \\
\hline Eschlibach & 12 & 4.1 & $\begin{array}{r}1,135,006 \\
( \pm 1,249)\end{array}$ & $\begin{array}{c}14,211.1 \\
( \pm 160.6)\end{array}$ & $\begin{array}{c}324.3 \\
( \pm .5)\end{array}$ & $\begin{array}{c}258.5 \\
( \pm .3)\end{array}$ \\
\hline Hepbach & 13 & 3.8 & $\begin{array}{r}231,020 \\
( \pm 622)\end{array}$ & $\begin{array}{c}2,892.5 \\
( \pm 74.4)\end{array}$ & $\begin{array}{c}182.5 \\
( \pm .7)\end{array}$ & $\begin{array}{l}52.6 \\
( \pm .1)\end{array}$ \\
\hline Imbersbach & 11 & 3.3 & $\begin{array}{r}139,222 \\
( \pm 613)\end{array}$ & $\begin{array}{c}1,743.2 \\
( \pm 49.7)\end{array}$ & $\begin{array}{l}121.4 \\
( \pm 1.2)\end{array}$ & $\begin{array}{l}31.7 \\
( \pm .1)\end{array}$ \\
\hline Mannenbach & 15 & 4.8 & $\begin{array}{r}1,464,130 \\
( \pm 1,408)\end{array}$ & $\begin{array}{l}18,331.9 \\
( \pm 196.1)\end{array}$ & $\begin{array}{c}392.4 \\
( \pm .6)\end{array}$ & $\begin{array}{c}333.4 \\
( \pm .3)\end{array}$ \\
\hline Seebach & 11 & 3.2 & $\begin{array}{r}1,370,115 \\
( \pm 1,250)\end{array}$ & $\begin{array}{c}17,154.8 \\
( \pm 153.2)\end{array}$ & $\begin{array}{c}270.8 \\
( \pm .4)\end{array}$ & $\begin{array}{c}312.0 \\
( \pm .3)\end{array}$ \\
\hline Tobelmühlibach & 12 & 3.7 & $\begin{array}{r}696,563 \\
( \pm 1,081)\end{array}$ & $\begin{array}{c}8,721.5 \\
( \pm 118.7)\end{array}$ & $\begin{array}{c}247.4 \\
( \pm .5)\end{array}$ & $\begin{array}{c}158.5 \\
( \pm .2)\end{array}$ \\
\hline $\begin{array}{l}\text { Unnamed } \\
\text { stream } 1\end{array}$ & 9 & 2.8 & $\begin{array}{r}518,543 \\
( \pm 849)\end{array}$ & $\begin{array}{c}6,492.5 \\
( \pm 133.0)\end{array}$ & $\begin{array}{c}177.7 \\
( \pm .7)\end{array}$ & $\begin{array}{c}118.1 \\
( \pm .2)\end{array}$ \\
\hline $\begin{array}{l}\text { Unnamed } \\
\text { stream } 2\end{array}$ & 10 & 3.6 & $\begin{array}{r}317,053 \\
( \pm 672)\end{array}$ & $\begin{array}{c}3,969.7 \\
( \pm 70.7)\end{array}$ & $\begin{array}{r}241.4 \\
( \pm .5)\end{array}$ & $\begin{array}{l}72.2 \\
( \pm .2)\end{array}$ \\
\hline
\end{tabular}

Note: The first two processing scenarios are based on our laboratory data of leaf litter consumption rates: scenario 1 assumes density-independent per capita processing, while scenario 2 assumes density-dependent leaf consumption calculated for each stream reach's interpolated density. The third estimate is based on the metabolic requirement for growth and respiration, assuming $40 \%$ assimilation of ingested leaf litter. Estimates are means of 1,000 simulations of total abundance, with $95 \%$ confidence intervals shown in parentheses. For streams, $n$ gives the number of sampling points in the catchment, while length equals total stream length in the catchment.

consumption requirement, while in a densely inhabited but sparsely vegetated catchment (Seebach), it was only eight times the estimated consumption.

\section{Discussion}

As ecology moves toward a more predictive science, a central challenge is that mechanisms underlying a response observed at one scale - for example, ecosystem function - are occurring at a different scale (Levin 1992). In this context, the nonlinear relationships abundant in nature present challenges for scaling up. Often, it may be necessary to incorporate variance in the explanatory variable - and not simply mean values - for predictions to be accurate: as Jensen's inequality states, variance and skewness influence the integrals of nonlinear functions (Ruel and Ayres 1999; Martin and Huey 2008; Denny and Benedetti-Cecchi 2012). Using experimental manipulations at the level of individual small organisms, we found that local population density had a strong effect on leaf litter processing rates of two dominant freshwater detritivores and thus their per capita (or per biomass) contribution to ecosystem function. At the reach scale, the shape of this DEF relationship meant that estimated ecosystem function was similar across stream reaches, even when there was substantial spatial heterogeneity in organismal abundances. At the landscape scale - that is, the scale of riverine networks - the shape of this nonlinear relationship had strong implications for scaled-up predictions of ecosystem function, because population density increases much faster than its corresponding ecosystem function. As a result, ecosystem function predictions based on our experimentally derived DEF relationship were more than an order of magnitude lower than predictions made using more simplistic, mean-based estimates. Predictions based on DEF relationships also better aligned with the estimated consumption rate needed to meet the metabolic requirements of a catchment's population. Thus neglecting the role of density may systematically bias estimates of ecosystem function and lead to unrealistic predictions.

Intraspecific competition for resources is an essential regulator of population dynamics. Here we demonstrate that intraspecific density could also regulate leaf litter processing, a key ecosystem function globally providing 

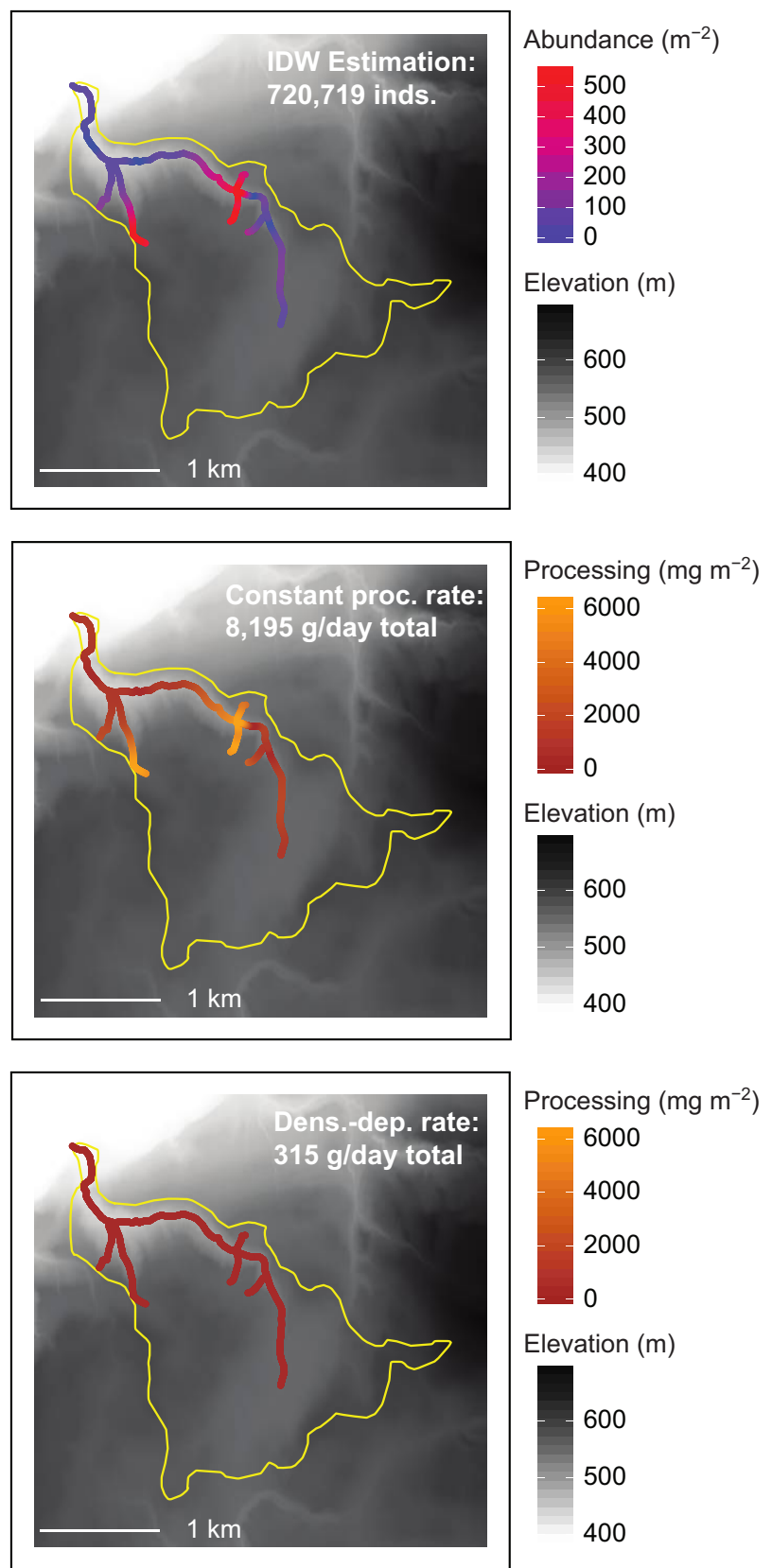

Figure 2: Hot spots of abundance (top) and leaf litter processing (center, bottom) in the Chesselbach stream catchment (outlined in yellow), based on scaling up abundance data from 13 sampling points up to longitudinal abundance distributions using inverse distance weighted interpolation. Daily processing rates were calculated by multiplying the interpolated abundance in a $1-\mathrm{m}$ section of stream length by either the average per capita consumption rate of Gammarus fossarum (center) or the experimentally derived negative power function relating $G$. fossarum density to per capita leaf litter consumption (bottom). This figure shows the mean of 1,000 simulations of the interpolation process. Because stream reaches with higher densities of individuals have the lowest per capita processing rates, the spatial distribution of leaf litter processing terrestrial resources to freshwater ecosystems (Tank et al. 2010; Hines et al. 2016; Gounand et al. 2018). Previously, leaf litter processing was shown to vary nonlinearly with abundance of macroinvertebrates, which was attributed to intraspecific competition for resources at high densities (Klemmer et al. 2012). However, in our experiments, resources were not limiting, and per capita leaf processing decreased even at relatively low densities. Thus, we suggest two reasons for higher per capita consumption at lower densities. First, we find it likely that interference competition (Schoener 1983) - competition for space rather than food resources (Moksnes 2004; Ward et al. 2007) — generated some of these nonlinearities. Second, our estimates of the metabolic requirements of different catchments' populations suggest that individuals consume more than needed at low densities, while this interference competition reduces consumption rates to the metabolic minimum at high densities. In the broader context of scaling up, all mechanisms of intraspecific interaction, including exploitation and interference competition, are important as they could shape DEF relationships.

One main consequence of a nonlinear DEF relationship is that predictions at the landscape scale become challenging. This is especially relevant for organisms that are known to vary in their abundance locally over several orders of magnitude, such as the dominant shredders studied here. In our case, neglecting the role of density would lead to vast overestimates of ecosystem function; in other contexts (species, relationships, and functions), the reverse may be true. Here the magnitude of overestimation depends on the mean consumption rate used for density-independent scaling up. Mean consumption rates from experiments where individuals were kept in tanks at a high density would lead to less drastic overestimation than those from experiments where individuals are kept alone in microcosms, as is common in amphipod laboratory experiments (reviewed in Little and Altermatt 2018c). Thus, knowing the DEF curve could help identify which experimental data could lead to less biased scaled-up estimates, even where linear extrapolations are used. Connecting nonlinear population dynamics and spatial heterogeneity led to the development of scale transition theory (Melbourne and Chesson 2005; Chesson 2012), which has been applied to populations and communities and should be expanded to ecosystem-level processes. This nonlinear spatial averaging effect is likely to be of interest for optimizing regional ecosystem function. For example, extremely high densities of organisms may not provide the most bang for their buck in contributing to ecosystem

under this scenario is very different from the spatial distribution of amphipod abundance, with the effect of homogenizing ecosystem function in space despite having heterogeneous biomass. Data sources: swisstopo $(2010,2014)$. 


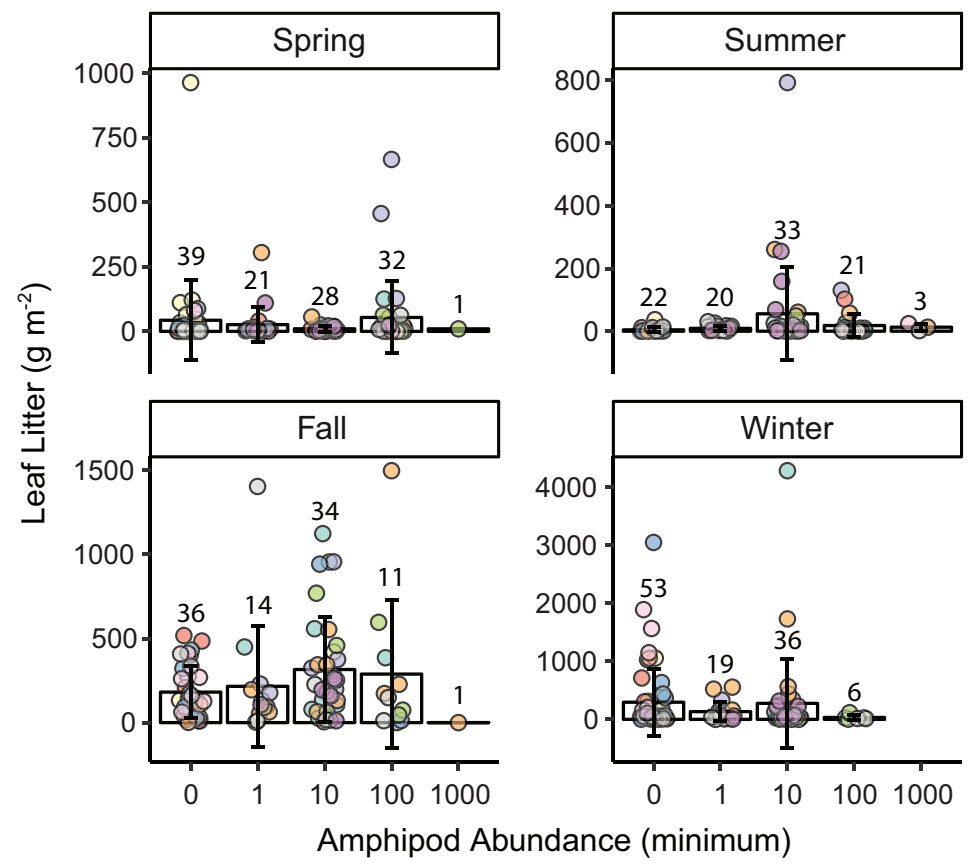

$\begin{array}{cl}\text { Stream } \\ \circ & \text { Chesselbach } \\ \circ & \text { Dorfbach } \\ \circ & \text { Eschlibach } \\ \circ & \text { Hepbach } \\ \circ & \text { Imbersbach } \\ \circ & \text { Mannenbach } \\ \circ & \text { Seebach } \\ \circ & \text { Tobelmühlibach } \\ \circ & \text { Unnamed } 1 \\ \circ & \text { Unnamed } 2\end{array}$

Figure 3: Standing stock of benthic leaf litter at sampling points where different abundance classes of amphipods were observed. Error bars show standard deviations of observations within an abundance class, and colored points show raw values. Numbers above the error bars indicate the number of sampling points falling into each abundance class in each sampling visit. Note that the $Y$-axis is transformed and has a different range for each season.

function, since each additional individual contributes less and less; as such, some intermediate abundance may lead to maximal functioning. In another perspective, this could be an argument for maintaining environmental heterogeneity and patches with high and low organismal abundance throughout a landscape. Even patches with relatively low density may have good ecosystem function, but source patches with high density are needed in order to supply colonists for sink patches, which are more subject to demographic stochasticity (Hanski and Simberloff 1997), even if those high-density patches do not necessarily have substantially higher ecosystem function themselves.

Our scaling-up exercise relies on several simplifying assumptions, discussed in full in table S2. One central assumption was that the taxa in question are providing the bulk of the ecosystem function studied. Indeed, amphipods are numerically dominant among all macroinvertebrates in many European forested headwater streams, and their shredding function cannot easily be replaced by other taxa (Piscart et al. 2009; Nery and Schmera 2015). Furthermore, in these forested headwaters, our two lines of evidence suggested that abundance of these consumers - rather than leaf litter supply rates - should limit leaf litter processing (figs. 3, 4). First, higher shredder abundances are not associated with higher leaf litter standing stock. Locally, leaf litter availability remained high even in some reaches with high densities of shredders. This was matched by our catchmentscale examination of leaf litter supply. Annual leaf litter inputs - estimated using several intentionally conservative assumptions - are one to several orders of magnitude greater than estimated consumption by spatially heterogeneous shredder populations feeding according to densitydependent behavior. Our measurements of vertical input during fall leaf were consistent with published estimates of annual leaf litter input from forested and riparian shrub habitats in the Northern Hemisphere (reviewed in Conners and Naiman 2008). While there is spatiotemporal variation in the availability of this annual input, a substantial amount is stored in streams by debris dams, snags, and other features (Tank et al. 2010) and remains available for many months (Little and Altermatt 2018c). At the same time, leaf litter is transported downstream. While many inputs are retained near their point of entry, benthic leaf litter standing stock is not strongly driven by local vegetation characteristics and is rather redistributed through a stream network (Little and Altermatt 2018b) and thus available to consumers distant from its point of origin. Leaf litter inputs are more likely to be limiting in larger rivers, where inputs are an order of magnitude less per unit area (Naiman and Decamps 1997).

Some other assumptions (table S2) limit the quantitative realism of our scaling-up exercise but should not alter our main conclusions. For example, it is unlikely that 


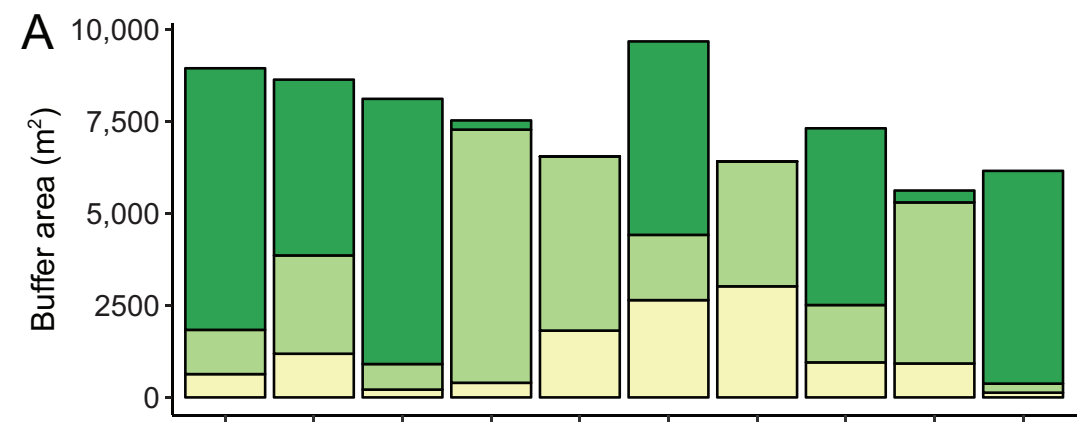

Buffer Cover Type

$\square$ Forested

Riparian vegetation

Other

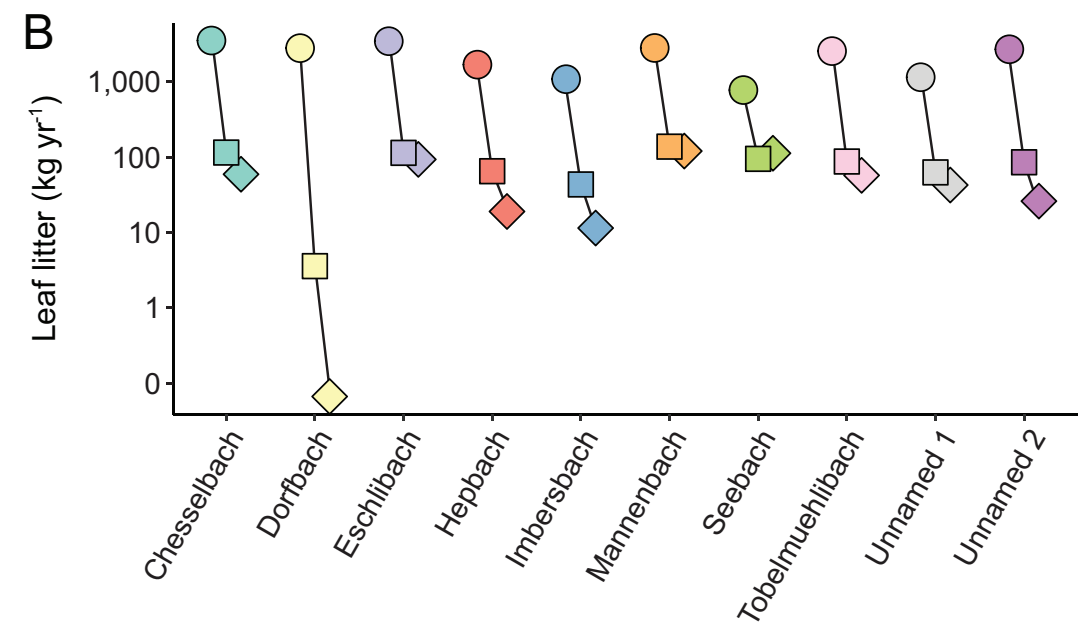

Estimate Type

$\bigcirc$ Leaf litter input

Density-dep. consumption

Metabolic requirement

Figure 4: Leaf litter availability at the catchment scale. $A$, Composition of the buffer area of each stream ( $1 \mathrm{~m}$ on either side) showing the area of potential input from forest and other riparian vegetation. $B$, Total potential leaf litter input in each catchment, based on composition of the buffer area in $A$, compared to total leaf litter consumption from estimated amphipod abundance and density-dependent consumption rates (table 1) and the estimated metabolic requirements of this same estimated population of amphipods. Note that the $Y$-axis is log transformed in $B$; the $X$-axis is the same for both panels.

the DEF relationship has the same parameters in natural streams with complex habitats as it does in simplified laboratory mesocosms. However, a negative power relationship should produce similar qualitative results in terms of identifying areas of the landscape with higher versus lower leaf litter processing, even if the shape of the densityconsumption relationship was somewhat different. To explore this further, we recalculated the scaled-up estimates of whole-catchment leaf litter processing using the experimentally derived parameters for D. villosus rather than $G$. fossarum (table S3). The two parameters differed by 25\% and $\sim 6 \%$ between the two species, which belong to different genera and are functionally distinct (Little and Altermatt 2018c). Catchment-scale leaf litter processing was quantitatively different (and higher) when parameterized with the $D$. villosus curve, but the rank order of total leaf litter processing between catchments was the same for almost all catchments (table S3); that is, qualitative differences between catchments were reproduced.
Future work should consider how other mechanisms might modify the DEF relationship and its implications for scaling up. For example, we focused on a single trophic level of consumers, but interspecific interactions including competition and predation also influence behavior, consumption rates, and ecosystem function (Werner and Peacor 2003; Hines and Gessner 2012); a multitrophic examination of the effects of dominant species density on ecosystem function is needed, including for cases unlike ours where resources are limiting and there is a functional response by consumers. Leaf litter quality and diversity could potentially affect the shape of DEF relationships by altering resource quality. It would also be of interest to investigate the assumption that the DEF relationship was the same in all patches, perhaps using simulation studies; habitat heterogeneity may alter organisms' perception of density and thus their behavior. Likewise, we doubt that temporal variation in the parameters of the DEF relationship would alter qualitative results; however, simulations could explore how 
seasonal changes in water temperature and population age/ size structure (Pöckl et al. 2003) would affect quantitative predictions of catchment-scale ecosystem function. Notably, some of these assumptions (such as seasonality and temporal averaging) could affect all extrapolations from laboratory to field estimates, regardless of whether density dependence is incorporated.

Our results expand the current understanding of biodiversity effects on ecosystem function to include densitydependent effects on ecosystem function, recognizing that nonlinear dependencies are prevalent and important (Grace et al. 2007; O'Connor et al. 2017). In fact, the two frameworks are related: release from intraspecific competition has been discussed as a mechanism through which increasing species richness accelerates ecosystem function (Jonsson and Malmqvist 2003; Weis et al. 2007; Patrick 2013). Connecting plot- and patch-level results to real, complex ecosystems and larger scales is recognized as one of the biggest challenges in ecosystem function research, with some debate as to the success of efforts to date (Hewitt et al. 2007; Snelgrove et al. 2014; Eisenhauer et al. 2016; Wardle 2016). Our results suggest that in some contexts, DEF may be extremely important: even without considering interactions with other species, intraspecific dynamics can be a strong control on ecosystem function, and thus accounting for organisms' interactions will be essential in determining the drivers of ecosystem function.

\section{Acknowledgments}

We thank Samuel Hürlemann and Remo Wüthrich for assisting with experiments and Pravin Ganesanandamoorthy, Elvira Mächler, Simon Flückiger, and Katharina Kaelin for fieldwork help. We additionally thank the Kanton Thurgau Office of the Environment and all landowners whose property we crossed. C.J.L. would like to thank the Eawag Eco PhD student writing group, organized by Heidi Kaech, for support and accountability; Joey Bernhardt and Simon Hart for valuable discussion; and Roman Alther and Isabelle Gounand for helpful comments on early drafts of the manuscript. We are grateful to Volker Rudolf and two anonymous reviewers for their feedback. This is publication ISEM-2019-148 of the Institut des Sciences de l'Evolution-Montpellier. Funding was provided by grants from the Swiss National Science Foundation (PP00P3_150698 and PP00P3_179089) and the University of Zurich Research Priority Programme Global Change and Biodiversity (to F.A.).

\section{Literature Cited}

Altermatt, F. 2013. Diversity in riverine metacommunities: a network perspective. Aquatic Ecology 47:365-377.
Altermatt, F., R. Alther, and E. Mächler. 2016. Spatial patterns of genetic diversity, community composition and occurrence of native and non-native amphipods in naturally replicated tributary streams. BMC Ecology 16:23.

Amarasekare, P. 2003. Competitive coexistence in spatially structured environments: a synthesis. Ecology Letters 6:1109-1122.

Bannar-Martin, K. H., C. T. Kremer, S. K. M. Ernest, M. A. Leibold, H. Auge, J. Chase, S. A. J. Declerck, et al. 2018. Integrating community assembly and biodiversity to better understand ecosystem function: the community assembly and the functioning of ecosystems (CAFE) approach. Ecology Letters 21:167-180.

Bates, D., M. Maechler, and B. Bolker. 2015. lme4: linear mixed-effects models using S4 classes. https://cran.r-project.org/web/packages /Ime4/index.html.

Birtel, J., and B. Matthews. 2016. Grazers structure the bacterial and algal diversity of aquatic metacommunities. Ecology 97:3472-3484.

Bossard, M., J. Feranec, and J. Otahel. 2000. The revised and supplemented Corine land cover nomenclature. European Environment Agency, Copenhagen.

Brook, B. W., and C. J. A. Bradshaw. 2006. Strength of evidence for density dependence in abundance time series of 1198 species. Ecology 87:1445-1451.

Brown, B. L., C. M. Swan, D. A. Auerbach, E. H. Campbell Grant, N. P. Hitt, K. O. Maloney, and C. Patrick. 2011. Metacommunity theory as a multispecies, multiscale framework for studying the influence of river network structure on riverine communities and ecosystems. Journal of the North American Benthological Society 30:310-327.

Cardinale, B. J., K. L. Matulich, D. U. Hooper, J. E. Byrnes, E. Duffy, L. Gamfeldt, P. Balvanera, M. I. O'Connor, and A. Gonzalez. 2011. The functional role of producer diversity in ecosystems. American Journal of Botany 98:572-592.

Carrara, F., A. Giometto, M. Seymour, A. Rinaldo, and F. Altermatt. 2015. Experimental evidence for strong stabilizing forces at high functional diversity of aquatic microbial communities. Ecology 96:1340-1350.

Chesson, P. 2000. Mechanisms of maintenance of species diversity. Annual Review of Ecology and Systematics 31:343-366.

- 2012. Scale transition theory: its aims, motivations and predictions. Ecological Complexity 10:52-68.

Conners, M. E., and R. J. Naiman. 2008. Particulate allochthonous inputs: relationships with stream size in an undisturbed watershed. Canadian Journal of Fisheries and Aquatic Sciences 41:1473-1484.

Covich, A. P., J. H. Thorp, and D. C. Rogers. 2010. Introduction to the subphylum Crustacea. Pages 695-723 in J. H. Thorp and A. P. Covich, eds. Ecology and classification of North American freshwater invertebrates. 3rd ed. Elsevier, London.

Cummins, K. W. 1975. Macroinvertebrates. Pages 170-198 in B. A. Whitton, ed. River ecology. University of California Press, Berkeley.

Dangles, O., and B. Malmqvist. 2004. Species richness-decomposition relationships depend on species dominance. Ecology Letters 7:395-402.

Delong, M. D., and M. A. Brusven. 1994. Allochthonous input of organic matter from different riparian habitats of an agriculturally impacted stream. Environmental Management 18:59-71.

Denny, M., and L. Benedetti-Cecchi. 2012. Scaling up in ecology: mechanistic approaches. Annual Review of Ecology, Evolution and Systematics 43:1-22.

Downing, A. L., and M. A. Leibold. 2002. Ecosystem consequences of species richness and composition in pond food webs. Nature 416:837-841. 
Drakou, E. G., D. C. Bobori, A. S. Kallimanis, A. D. Mazaris, S. P. Sgardelis, and J. D. Pantis. 2009. Freshwater fish community structured more by dispersal limitation than by environmental heterogeneity. Ecology of Freshwater Fish 18:369-379.

Eisenhauer, N., A. D. Barnes, S. Cesarz, D. Craven, O. Ferlian, F. Gottschall, J. Hines, et al. 2016. Biodiversity-ecosystem function experiments reveal the mechanisms underlying the consequences of biodiversity change in real world ecosystems. Iournal of Vegetation Science 27:1061-1070.

Fisher, S. G., and G. E. Likens. 1973. Energy flow in Bear Brook, New Hampshire: an integrative approach to stream ecosystem metabolism. Ecological Monographs 43:421-439.

Gallardo, B., and D. C. Aldridge. 2015. Is Great Britain heading for a Ponto-Caspian invasional meltdown? Journal of Applied Ecology 52:41-49.

Gergs, R., and K. O. Rothhaupt. 2008. Feeding rates, assimilation efficiencies and growth of two amphipod species on biodeposited material from zebra mussels. Freshwater Biology 53:2494-2503.

Gounand, I., C. J. Little, E. Harvey, and F. Altermatt. 2018. Crossecosystem carbon flows connecting ecosystems worldwide. $\mathrm{Na}-$ ture Communications 9:4825.

Grace, J. B., T. M. Anderson, E. W. Seabloom, E. T. Borer, P. B. Adler, W. S. Harpole, Y. Hautier, et al. 2016. Integrative modelling reveals mechanisms linking productivity and plant species richness. Nature 529:390-393.

Grace, J. B., T. M. Anderson, M. D. Smith, E. Seabloom, S. J. Andelman, G. Meche, E. Weiher, et al. 2007. Does species diversity limit productivity in natural grassland communities? Ecology Letters 10:680-689.

Hanski, I. 1990. Density dependence, regulation and variability in animal populations. Philosophical Transactions of the Roval Societv B 330:141-150.

Hanski, I., and D. Simberloff. 1997. The metapopulation approach, its history, conceptual domain, and application to conservation. Pages 5-26 in I. Hanski and M. E. Gilpin, eds. Metapopulation biology: ecology, genetics, and evolution. Academic Press, San Diego, CA.

Harvey, L. D. D. 2000. Upscaling in global change research. Climatic Change 44:225-263.

Hassell, M. P., J. H. Lawton, and R. M. May. 1976. Patterns of dynamical behavior in single species populations. Journal of Animal Ecology 45:471-486.

Hewitt, J. E., S. F. Thrush, P. K. Dayton, and E. Bonsdorff. 2007. The effect of spatial and temporal heterogeneity on the design and analysis of empirical studies of scale-dependent systems. American Naturalist 169:398-408.

Hieber, M., and M. O. Gessner. 2002. Contribution of stream detrivores, fungi, and bacteria to leaf breakdown based on biomass estimates. Ecology 83:1026-1038.

Hillebrand, H., D. M. Bennett, and M. W. Cadotte. 2008. Consequences of dominance: a review of evenness effects on local and regional ecosystem processes. Ecology 89:1510-1520.

Hines, J., and M. O. Gessner. 2012. Consumer trophic diversity as a fundamental mechanism linking predation and ecosystem functioning. Journal of Animal Ecology 81:1146-1153.

Hines, J., M. Reyes, and M. O. Gessner. 2016. Density constrains cascading consequences of warming and nitrogen from invertebrate growth to litter decomposition. Ecology 97:1635-1642.

Jensen, J. L. W. V. 1906. Sur les fonctions convexes et les inégalités entre les valeurs moyennes. Acta Mathematica 30:175-193.
Jonsson, M., and B. Malmqvist. 2003. Mechanisms behind positive diversity effects on ecosystem functioning: testing the facilitation and interference hypotheses. Oecologia 134:554-559.

Kingsolver, J. G. 2009. The well-temperatured biologist. American Naturalist 174:755-768.

Klemmer, A. J., S. A. Wissinger, H. S. Greig, and M. L. Ostrofsky. 2012. Nonlinear effects of consumer density on multiple ecosystem processes. Journal of Animal Ecology 81:770-780.

Kochi, K., Y. Mishima, and A. Nagasaka. 2010. Lateral input of particulate organic matter from bank slopes surpasses direct litter fall in the uppermost reaches of a headwater stream in Hokkaido, Japan. Limnology 11:77-84.

Kuznetsova, A., P. B. Brockhoff, and R. H. B. Christensen. 2015. lmerTest: tests in linear mixed effects models. https://cran.r-project .org/web/packages/ImerTest/index.html.

Levin, S. A. 1992. The problem of pattern and scale in ecology. Ecology 73:1943-1967.

Little, C. J., and F. Altermatt. 2018a. Do priority effects outweigh environmental filtering in a guild of dominant freshwater macroinvertebrates? Proceedings of the Roval Societv B 285:20180205.

- 2018b. Landscape configuration alters spatial arrangement of terrestrial-aquatic subsidies in headwater streams. Landscape Ecology 33:1519-1531.

. 2018c. Species turnover and invasion of dominant freshwater invertebrates alter biodiversity-ecosystem-function relationship. Ecological Monographs 88:461-480.

Little, C. J., E. A. Fronhofer, and F. Altermatt. 2020. Data from: Nonlinear effects of intraspecific competition alter landscape-wide scaling up of ecosystem function. American Naturalist, Dryad Digital Depository, https://doi.org/10.5061/dryad.3124p62.

Loreau, M., N. Mouquet, and A. Gonzalez. 2003. Biodiversity as spatial insurance in heterogeneous landscapes. Proceedings of the National Academy of Sciences of the USA 100:12765-12770.

Marchant, R., and H. B. N. Hynes. 1981. The distribution and production of Gammarus pseudolimnaeus (Crustacea: Amphipoda) along a reach of the Credit River, Ontario. Freshwater Biology 11:169-182.

Martin, T. L., and R. B. Huey. 2008. Why "suboptimal" is optimal: Jensen's inequality and ectotherm thermal preferences. American Naturalist 171:E102-E118.

McPeek, M. A. 2012. Intraspecific density dependence and a guild of consumers coexisting on one resource. Ecology 93:2728-2735.

Melbourne, B. A., and P. Chesson. 2005. Scaling up population dynamics: integrating theory and data. Oecologia 145:179-187.

Moksnes, P. O. 2004. Interference competition for space in nursery habitats: density-dependent effects on growth and dispersal in juvenile shore crabs Carcinus maenas. Marine Ecology Progress Series 281:181-191.

Moore, J. W., and J. D. Olden. 2017. Response diversity, nonnative species, and disassembly rules buffer freshwater ecosystem processes from anthropogenic change. Global Change Biology 23:1871-1880.

Mortensen, E. 1982. Production of Gammarus pulex L. (Amphipoda) in a small Danish stream. Hydrobiologia 87:77-97.

Naiman, R. J., and H. Decamps. 1997. The ecology of interfaces: riparian zones. Annual Review of Ecology and Systematics 28:621-658.

Nery, T., and D. Schmera. 2015. The effects of top-down and bottomup controls on macroinvertebrate assemblages in headwater streams. Hydrobiologia 763:173-181.

O'Connor, M. I., A. Gonzalez, J. E. K. Byrnes, B. J. Cardinale, J. E. Duffy, L. Gamfeldt, J. N. Griffin, et al. 2017. A general biodiversityfunction relationship is mediated by trophic level. Oikos 126:18-31. 
Parain, E. C., R. P. Rohr, S. M. Gray, and L.-F. Bersier. 2018. Increased temperature disrupts the biodiversity-ecosystem functioning relationship. American Naturalist 193:227-239.

Patrick, C. J. 2013. The effect of shredder community composition on the production and quality of fine particulate organic matter. Freshwater Science 32:1026-1035.

Pebesma, E. J. 2004. Multivariable geostatistics in S: the gstat package. Computers and Geosciences 30:683-691.

Petersen, R. C., K. W. Cummins, and G. M. Ward. 1989. Microbial and animal processing of detritus in a woodland stream. Ecological Monographs 59:21-39.

Pinheiro, J., D. Bates, S. DebRoy, D. Sarkar, and R Core Development Team. 2013. nlme: linear and nonlinear mixed effects models. https://cran.r-project.org/web/packages/nlme/index.html.

Piscart, C., R. Genoel, S. Doledec, E. Chauvet, and P. Marmonier. 2009. Effects of intense agricultural practices on heterotrophic processes in streams. Environmental Pollution 157:1011-1018.

Piscart, C., F. Mermillod-Blondin, C. Maazouzi, S. Merigoux, and P. Marmonier. 2011. Potential impact of invasive amphipods on leaf litter recycling in aquatic ecosystems. Biological Invasions 13:2861-2868.

Pöckl, M., B. W. Webb, and D. W. Sutcliffe. 2003. Life history and reproductive capacity of Gammarus fossarum and G. roeseli (Crustacea: Amphipoda) under naturally fluctuating water temperatures: a simulation study. Freshwater Biology 48:53-66.

Raffard, A., F. Santoul, J. Cucherousset, and S. Blanchet. 2019. The community and ecosystem consequences of intraspecific diversity: a meta-analysis. Biological Reviews 94:648-661.

R Core Team. 2018. R: a language and environment for statistical computing. R Foundation for Statistical Computing, Vienna.

Rüegg, J., G. A. Lamberti, S. D. Tiegs, P. S. Levi, D. T. Chaloner, and J. L. Tank. 2011. Salmon subsidies alleviate nutrient limitation of benthic biofilms in southeast Alaska streams. Canadian Journal of Fisheries and Aquatic Sciences 68:277-287.

Ruel, J. J., and M. P. Ayres. 1999. Jensen's inequality predicts effects of environmental variation. Trends in Ecology and Evolution 5347:361-366.

Sarremejane, R., H. Mykrä, N. Bonada, J. Aroviita, and T. Muotka. 2017. Habitat connectivity and dispersal ability drive the assembly mechanisms of macroinvertebrate communities in river networks. Freshwater Biology 62:1073-1082.

Scarsbrook, M. R., J. M. Quinn, J. Halliday, and R. Morse. 2001. Factors controlling litter input dynamics in streams draining pasture, pine, and native forest catchments. New Zealand Journal of Marine and Freshwater Research 35:751-762.

Schoener, T. W. 1983. Field experiments on interspecific competition. American Naturalist 122:240-285.

Šidagytė, E., S. Solovjova, V. Šniaukštaitè, A. Šiaulys, S. Olenin, and K. Arbačiauskas. 2017. The killer shrimp Dikerogammarus villosus (Crustacea, Amphipoda) invades Lithuanian waters, south-eastern Baltic Sea. Oceanologia 59:85-91.

Smith, M. D., and A. K. Knapp. 2003. Dominant species maintain ecosystem function with non-random species loss. Ecology Letters 6:509-517.
Snelgrove, P. V. R., S. F. Thrush, D. H. Wall, and A. Norkko. 2014. Real world biodiversity-ecosystem functioning: a seafloor perspective. Trends in Ecology and Evolution 29:398-405.

swisstopo. 2007. Vector 25 Gewässernetz. 5704000 000, reproduced by permission of swisstopo/JA100119, Bundesamt für Landestopographie (Art.30 Geo IV).

- 2010. Vector 25. 5704000 000, reproduced by permission of swisstopo/JA100119, Bundesamt für Landestopographie (Art.30 Geo IV).

- 2014. swissTLM3D. 5704000 000, reproduced by permission of swisstopo/JA100119, Bundesamt für Landestopographie (Art.30 Geo IV).

- 2016. SWISSIMAGE. 5704000 000, reproduced by permission of swisstopo/JA100119, Bundesamt für Landestopographie (Art.30 Geo IV).

Tank, J. L., E. J. Rosi-Marshall, N. A. Griffiths, S. A. Entrekin, and M. L. Stephen. 2010. A review of allochthonous organic matter dynamics and metabolism in streams. Iournal of the North American Benthological Societv 29:118-146.

Van den Brink, F. W. B., G. Van der Velde, and A. Bij de Vaate. 1991. Amphipod invasion on the Rhine. Nature 352:576.

Ward, D. M., K. H. Nislow, J. D. Armstrong, S. Einum, and C. L. Folt. 2007. Is the shape of the density-growth relationship for stream salmonids evidence for exploitative rather than interference competition? Iournal of Animal Ecology 76:135-138.

Wardle, D. A. 2016. Do experiments exploring plant diversityecosystem functioning relationships inform how biodiversity loss impacts natural ecosystems? Journal of Vegetation Science 27:646653.

Weis, J. J., B. J. Cardinale, K. J. Forshay, and A. R. Ives. 2007. Effects of species diversity on community biomass production change over the course of succession. Ecology 88:929-939.

Welton, J. S. 1979. Life-history and production of the amphipod Gammarus pulex in a Dorset chalk stream. Freshwater Biology 9:263-275.

Werner, E. E., and S. D. Peacor. 2003. A review of trait-mediated indirect interactions in ecological communities. Ecology 84:1083-1100.

Winder, M., and D. E. Schindler. 2004. Climate change uncouples trophic interactions in an aquatic ecosystem. Ecology 85:2100-2106.

Winfree, R., J. W. Fox, N. M. Williams, J. R. Reilly, and D. P. Cariveau. 2015. Abundance of common species, not species richness, drives delivery of a real-world ecosystem service. Ecology Letters 18:626635.

Yachi, S., and M. Loreau. 1999. Biodiversity and ecosystem productivity in a fluctuating environment: the insurance hypothesis. Proceedings of the National Academv of Sciences of the USA 96:1463-1468.

Zhang, H., E. S. Rutherford, D. M. Mason, J. T. Breck, M. E. Wittmann, R. M. Cooke, D. M. Lodge, et al. 2016. Forecasting the impacts of silver and bighead carp on the Lake Erie food web. Transactions of the American Fisheries Society 145:136-162.

Associate Editor: Volker H. W. Rudolf Editor: Alice A. Winn 